\title{
Empirical Model for Heat Transfer of Electric Submersible Pump (ESP) Motor at Oil Producer Well
}

Gunawan ${ }^{1}$, Idral Amri ${ }^{1}$, Bahruddin ${ }^{1}$

${ }^{1}$ Department of Chemical Engineering, Faculty of Engineering, University Riau

Kampus Bina Widya Km 12,5 Simpang Baru Pekanbaru 28293 - Indonesia

Corresponding Author: gunawan6297@grad.unri.ac.id

\begin{tabular}{|c|c|}
\hline Article History: & Abstract \\
\hline $\begin{array}{l}\text { Received: } 29 \text { Mar } 2019 \\
\text { Receive in Revised Form: } 11 \text { Sep } 2019 \\
\text { Accepted: } 19 \text { Sep } 2019\end{array}$ & \multirow{3}{*}{$\begin{array}{l}\text { Motor operating temperature at wells equipped with Electric } \\
\text { Submersible Pump (ESP) needs to be monitored to maintain ESP } \\
\text { performance run life. Not all producer wells equipped with } \\
\text { temperature sensors, so it considered necessary to build a } \\
\text { mathematic model to estimate motor operating temperature. Model } \\
\text { of heat transfer to predict motor operating temperature is developed } \\
\text { based on the empirical equation method. Parameter and variable } \\
\text { data obtained from producer wells include fluid rate, water cut, } \\
\text { viscosity, specific gravity, operating temperature, ampere, and } \\
\text { voltage. The procedure to calculate viscosity is ASTM D- } 88 \text { and the } \\
\text { procedure to calculate specific gravity is ASTM D-5002. From } 18 \\
\text { wells data obtained from the field, calculated Reynold numbers } \\
\text { indicate a turbulent flow regime with Reynold numbers more than } \\
4,000 \text {. Nusselt number was calculated using multiple linear } \\
\text { regression with the result of Nu }=0.06 * \text { Re } e^{0.65} * \text { Pr }{ }^{0.36} \text { with an error } \\
\text { of } 1.3 \% \text { from downhole sensor measurement. The comparison with } \\
\text { similar research also provided that use different Nusselt number } \\
\text { empirical equation. The conclusion from the research showing that } \\
\text { an empirical approach by using specific constants to predict Nusselt } \\
\text { number can be used to predict a more accurate heat transfer } \\
\text { coefficient with an error of } 1.3 \% \text {. Higher water cut fluid flow need } \\
\text { lower fluid velocity to achieve motor operating temperature below } \\
\text { motor limit temperature with a fluid velocity above } 0.3 \text { m/s. }\end{array}$} \\
\hline Keywords: & \\
\hline $\begin{array}{l}\text { Annuli flow, empirical approach for nusselt } \\
\text { number, forced convection, heat transfer, } \\
\text { turbulent fluid flow. }\end{array}$ & \\
\hline
\end{tabular}

\section{INTRODUCTION}

Electric Submersible Pump (ESP) is an artificial lift method that capable to deliver high volumes of fluid from reservoirs. In ESP operations, electric energy is transported to the down-hole electric motor via the electric cables. These electric cables are run on the side of (and are attached to) the production tubing. The electric cable provides the electrical energy needed to actuate the downhole electric motor. The electric motor drives the pump and the pump imparts energy to the fluid in the form of hydraulic power, which lifts the fluid to the surface (Guo, Lyons, \& Ghalambor, 2007).

Controlling motor temperature is important for increasing ESP run life as motor temperature plays a key role in motor failures. Power losses in ESP motors were analyzed for various operating conditions. The internal motor temperature depends upon heat generation in the motor, well parameters, operating conditions, as well as the design and materials used to manufacture the motor (Bough, Orrego, Waldner, Ulc, \& Sheth, 2014). Ideally, the temperature during ESP operation can be measured using a downhole temperature sensor that attached to the ESP motor. But only a few producer wells equipped with a downhole temperature sensor, therefore, it's essential to design a computational approach model to predict the temperature of ESP motor during operation. In this situation, forced convection heat transfer is applied to model the problem. Forced convection heat transfer occurs when the flow patterns are determined primarily by some external force. The Nusselt number depends on the Reynolds and Prandtl numbers (Bird, Stewart, \& Lightfood, 2002). 
Forced convection heat transfer have been studied experimentally. Galvão (2015) analyzed forced convection in directional and vertical wells and proposed Nusselt number equation based on three flow regimes which are laminar, transient, and turbulent. Based on the experiment, comparisons between calculation and measurement from bottom hole sensors showing consistent and satisfactory results which is below $10{ }^{\circ} \mathrm{C}$. Bianco, Nardini, \& Manca (2011) investigated the heat transfer of nanofluids turbulent forced convection flow in square section tubes. The inclusion of nanoparticles produced a considerable increase in heat transfer compared to the base fluid. the experiment also concluded that heat transfer enhancement increased with the particle volume concentration. Oon (2014) studied the heat transfer of airflow in an annular pipe and showed that an increase of Reynolds number will affect the increase of Nusselt number. Skočilasová, Skočilas, \& Soukup (2018) proposed several Nusselt number equations with several conditions to predict forced convection of small tube inserted perpendicularly into the large pipe. Manca, Nardini, \& Ricci (2011) investigated water forced convection in channels with differently shaped transverse ribs to find optimal configuration in terms of high heat transfer coefficients and low losses. This work extends the investigation to find specific constants for Nusselt number equation to calculate ESP operating motor temperature.

\section{METHOD}

The studied fluid flow is shown in figure 1. The ESP motor is located concentric inside production casing with heat flux constant from the motor. Well operating condition data are taken from 18 producer wells in the field with the condition of well depth $1,500 \mathrm{~m}$, casing diameter $16,17 \mathrm{~cm}$, average motor length 4 $\mathrm{m}$, average reservoir temperature $115 \mathrm{C}$, average water cut $83 \%$, and average fluid production rate 132 $\mathrm{m}^{3} /$ day.

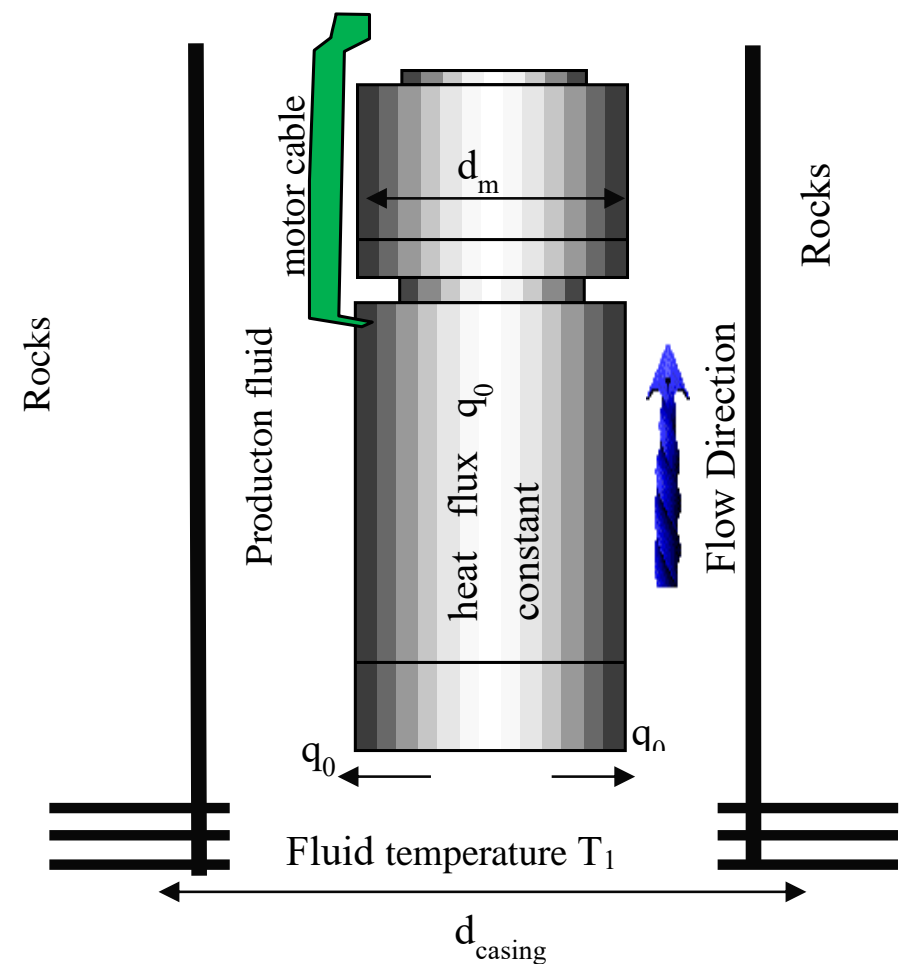

Figure 1. ESP motor inside producer well

Fluid samples are taken from the wellhead and fluid properties are measured by using ASTM D- 88 for dynamic viscosity using Anton Paar Density and Sound Velocity Meter DSA5000M, ASTM D-5002 for fluid density using Koehler viscosity meter with temperature control, ESP motor temperature measured by Phoenix XT-150 that attached to ESP motor.

Nusselt number $(\mathrm{Nu})$ is equal to the dimensionless temperature gradient at the surface, and it provides a measure of the convection heat transfer occurring at the surface (Incropera, Dewitt, Bergman, \& Lavine, 2008). Nusselt number can be determined by using the equation:

$$
\overline{N u}=\frac{\bar{h} D_{h}}{k}
$$


Using the empirical method, the Nusselt number equation can be represented by an algebraic expression of the form:

$$
\overline{N u}=C * R e^{m} * \operatorname{Pr}^{n}
$$

where $\mathrm{c}, \mathrm{m}, \mathrm{n}$ are constants.

Reynolds number is dimensionless number represents the ratio of the inertia to viscous forces. if the Reynolds number is small, inertia forces are insignificant relative to viscous forces. The disturbances are then dissipated, and the flow remains laminar. For a large Reynolds number, however, the inertia forces can be sufficient to amplify the triggering mechanisms, and a transition to turbulence occurs (Incropera et al., 2008). Galvão et al. (2015) suggested turbulent flow occurs when Reynolds number above 4,000. Reynolds number for flow through annuli can be determined by using expression (Sinnott, 2005) :

$$
R e=\frac{\rho . v \cdot 2(R-r)}{\mu} \text { or } R e=\frac{\rho v(D-d)}{\mu}
$$

Prandtl number is a dimensionless number represent a ratio of the momentum diffusivity to the thermal diffusivity. The Prandtl number provides a measure of the relative effectiveness of momentum and energy transport by diffusion in the velocity and thermal boundary layers, respectively (Incropera et al., 2008). Prandtl number can be determined by using the expression:

$$
\operatorname{Pr}=\frac{v}{\alpha}=\frac{\mu / \rho}{k / \rho C_{p}}=\frac{C p \mu}{k}
$$

Heat transfer coefficient for flow system with the fluid flowing either in a conduit or around a solid object can be determined by using expression (Bird et al., 2002) :

$$
Q=h \cdot A . \Delta T \text { atau } \Delta T=\frac{Q}{h \cdot A}
$$

where $\Delta \mathrm{T}=$ delta temperature between motor and fluid

The Nusselt number equation is change to linear form to be solved using multiple variable linear regression.

$$
\log N u=\log C+m \log R e+n \log P r
$$

\section{RESULTS AND DISCUSSION}

From 18 wells field data, Nusselt number empirical equation constant could be obtained by using multiple variable linear regression. The proposed Nusselt number constant is described in eq. 7.

$$
N u=0,06 * \operatorname{Re}^{0,65} * \operatorname{Pr}^{0,36}
$$

Based on eq. 7, the motor temperature can be estimated with the average error from sensor measurement $1.3 \%$. From the experiment, Reynolds number constant $(\mathrm{m})$ is 0.65 . Based on Incropera et al. (2008), Reynolds number constants is 0.5 for laminar flow at the flat plate, 0.618 for turbulent flow with flow perpendicular to the cylinder with Reynolds number from 4,000-40,000, and 0,8 for turbulent flow with Reynolds number more than 10,000. In this experiment, most of the Reynolds number in the range of 4,000-10,000 which is not exactly meet with the experiment condition. Reynolds number constant of 0.65 is between 0,5 and 0,8 due to different Reynolds number. Oil and water mixture flow in a vertical pipe can have different flow patterns that affect flow characteristics such as Reynolds number (Du, Jin, Gao, Wang, \& Zhai, 2012).

From the experiment, Prandtl number constant (n) is 0.36. Based on (Incropera et al., 2008), Prandtl number is 0.3 if the surface temperature is cooler than fluid temperature and 0.4 if the surface temperature is hotter than the fluid temperature. In this experiment, there is a possibility that heat transfer occurred not only from the motor surface to fluid but also from fluid to production casing to reservoir rocks. Prandtl number constant is 0.36 between 0.3 and 0.4 which possibility due to heat transfer from the system to the outside of the system. Overall Nusselt number equation constant $(C)$ is 0.06 which is within a range between laminar flow and turbulent flow with Reynolds number above 10,000. Nusselt number constant for laminar flow is 0.664 and turbulent flow above 10,000 is 0,023 (Incropera et al., 2008).

Some amount of research has done to predict Nusselt number related to heat transfer with forced convection experiment. The Nusselt number equation constants are different based on the fluid flow conditions, geometry and fluid type as follows: 
1. (Galvão et al., 2015) $N u=0,023 * R e^{0,8} * \operatorname{Pr}^{0,33}$

2. (Bianco et al., 2011) $N u=0,021 * \operatorname{Re}^{0,8} * \operatorname{Pr}^{0,5}$

3. (Oon et al., 2014) $N u=0,023 * R e^{0,8} * \operatorname{Pr}^{0,4}$

4. (Skočilasová et al., 2018) $N u=0,25 * \operatorname{Re}^{0,8} * \operatorname{Pr}^{\frac{1}{3}} *\left(\frac{d}{D}\right)^{0,2}$

5. (Manca et al., 2011) $N u=0,024 * \operatorname{Re}^{0,8} * \operatorname{Pr}^{0,4}$

Eq. 8 is proposed by Galvão et al. (2015) to predict Nusselt number at producer wells with Reynolds number lower than this experiment. Eq. 9 is proposed by Bianco et al. (2011) to predict Nusselt number of nanofluids turbulent convection flow in square section tubes with Reynolds number range from 5,000 to 100,000 and nanoparticle concentration of $1 \%, 4 \%$, and 6\%. Eq. 10 is proposed by Oon et al. (2014) to measure heat transfer in pipe annulus using air as cooling fluid and Reynolds number between 17,050 and 45,545. Eq. 11 is proposed by Skočilasová et al. (2018) to predict Nusselt number inside annulus flow with water as cooling fluid and Reynolds number between 3,000 and 35,000 and Prandtl number is 7. Eq. 12 is proposed by Manca et al. (2011) to predict convection in the turbulent flow that uses water as a cooling fluid inside the pipe with a hydraulic diameter of $20 \mathrm{~mm}$ and Reynolds number between 20,000 and 60,000 . Eq. 8 to Eq. 12 can be used to predict the motor temperature in this experiment with error range from $3.7 \%$ to $5.3 \%$. The error is possible due to several reasons such as differential geometry, fluid type, and fluid flow condition, different Reynolds number, and experiment boundary condition.

Based on Eq. 7, fluid velocity to maintain the motor temperature below $157^{\circ} \mathrm{C}$ can be determined (Figure 2).

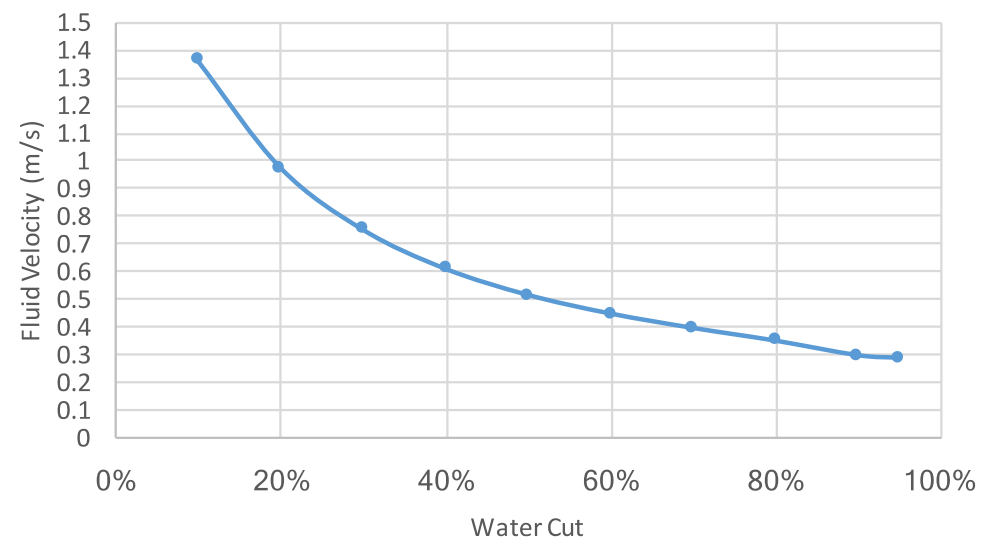

Figure 2. Correlation of water cut to fluid velocity to maintain the motor temperature

Higher water cut of production fluid has a higher heat capacity and thermal conductivity of fluid to get better heat transfer from the motor surface to production fluid. Thermal conductivity of water at $47^{\circ} \mathrm{C}$ is $0,6387 \mathrm{~W} /(\mathrm{m} . \mathrm{K})$ (Ramires \& Nieto de Castro, 1994) while thermal conductivity of crude oil at $47^{\circ} \mathrm{C}$ is 0,12 W/(m.K) (Elam, Tokura, Saito, \& Altenkirch, 1989). Crude oil heat capacity at $47{ }^{\circ} \mathrm{C}$ is 2,09 Joule/gram.C (Manning \& Thompson, 1995) while water heat capacity at $47{ }^{\circ} \mathrm{C}$ is 4,179 Joule/gram.C (Sharma, Sarma, Azmi, Mamat, \& Kadirgama, 2012). Figure 2 shows the correlation between water cut and fluid velocity to keep the motor temperature below $157{ }^{\circ} \mathrm{C}$ which is below the motor operating temperature limit. Observed fluid velocity is aligned with API recommended practice for sizing and selection of electrical submersible pump installations $11 \mathrm{~S} 4$ that proposed fluid velocity between $0.3 \mathrm{~m} / \mathrm{s}$ to $3.65 \mathrm{~m} / \mathrm{s}$ (American Petroleum Institute, 2013).

\section{CONCLUSION}

An empirical equation of Nusselt number is used to determine heat transfer from ESP motor to production fluid in producer well equipped with ESP and has been verified using a downhole temperature sensor. This study concludes that the empirical equation of Nusselt number with proposed constants produces a suitable correlation of heat transfer from ESP motor to production fluid with error $1.3 \%$ from sensor measurement. The local Nusselt number $(\mathrm{Nu})$ increases with the increase of Reynolds number which is valid for all cases. Higher water cut of production fluid affects fluid heat capacity and heat conductivity that need lower fluid velocity to maintain motor operating temperature. 


\section{Acknowledgments}

This research was supported by the Department of Chemical Engineering, Faculty of Engineering, Universitas Riau, Indonesia, and PT. Chevron Pacific Indonesia, Riau, Indonesia.

\section{Nomenclature}

$\mathrm{Nu} \quad$ Nusselt Number

Re Reynolds Number

Pr Prandtl Number

$\rho \quad$ fluid density $\left(\mathrm{kg} / \mathrm{m}^{3}\right)$

v fluid velocity $(\mathrm{m} / \mathrm{s})$

D casing inside diameter $(\mathrm{m})$

d motor outside diameter $(\mathrm{m})$

$\mathrm{Dh}_{\mathrm{h}} \quad$ hydrolic diameter $(\mathrm{m})$

$\mathrm{h}$ heat transfer coefficient $\left(\mathrm{W} / \mathrm{m}^{2} /{ }^{\circ} \mathrm{C}\right)$

$\mu \quad$ fluid viscosity $(\mathrm{kg} / \mathrm{m} / \mathrm{s})$

$\mathrm{Cp}$ Heat capacity $\left(\mathrm{J} / \mathrm{kg} /{ }^{\circ} \mathrm{C}\right)$

$\mathrm{k}$ thermal conductivity $\left(\mathrm{W} / \mathrm{m} /{ }^{\circ} \mathrm{C}\right)$

Q heat flow in to the fluid (Watt)

A area $\left(\mathrm{m}^{2}\right)$

$\Delta \mathrm{T}$ delta temperature motor to fluid $\left({ }^{\circ} \mathrm{C}\right)$

Tfluid fluid temperature $\left({ }^{\circ} \mathrm{C}\right)$

$\mathrm{T}_{\text {motor }}$ motor temperature $\left({ }^{\circ} \mathrm{C}\right)$

\section{References}

American Petroleum Institute. (2013). Recommended Practice for Sizing and Selection of Electric Submersible Pump Installations. API Recommended Practice 11S4 Third Edition, (October 2013).

Bianco, V., Nardini, S., \& Manca, O. (2011). Enhancement of Heat Transfer and Entropy Generation Analysis of Nanofluids Turbulent Convection Flow in Square Section Tubes. Journal Nanoscale Research Letters, 6(252), 1-12.

Bird, R. B., Stewart, W. E., \& Lightfood, E. N. (2002). Transport Phenomena Second Edition. United States of America: John Wiley \& Sons Inc.

Bough, M., Orrego, Y., Waldner, L., Ulc, N. E., \& Sheth, K. (2014). Enhanced Cooler-Operating ESP Motor Design and Field Trials. SPE Artificial Lift Conference and Exhibition-North America, SPE171347-MS. Houston-Texas. USA.

Du, M., Jin, N., Gao, Z., Wang, Z., \& Zhai, L. (2012). Flow Pattern and Water Holdup Measurements of Vertical Upward Oil - Water Two-phase Flow in Small Diameter Pipes. International Journal of Multiphase Flow, 41, 91-105. https://doi.org/10.1016/j.ijmultiphaseflow.2012.01.007

Elam, S. K., Tokura, I., Saito, K., \& Altenkirch, R. A. (1989). Thermal conductivity of crude oils. Experimental Thermal and Fluid Science, 2(1), 1-6. https://doi.org/10.1016/0894-1777(89)90043-5

Galvão, H. L. C., Oliva, G. B. F. F., Santos, D. P., Maitelli, A. L., Costa, R. O., \& Maitelli, C. W. S. P. (2015). Computational Model of Heat Transfer in ESP System for Deviated Wells. SPE Artificial Lift Conference - Latin America and Caribbbean SPE-173971-MS. Brazil.

Guo, B., Lyons, W. C., \& Ghalambor, A. (2007). Petroleum Production Engineering. In Petroleum Production Engineering. https://doi.org/10.1016/B978-075068270-1/50021-9

Incropera, F. P., Dewitt, D. P., Bergman, T. L., \& Lavine, A. S. (2008). Fundamentals of Heat and Mass Transfer. USA: John Wiley and Sons.

Manca, O., Nardini, S., \& Ricci, D. (2011). Numerical Analysis of Water Forced Convection in Channels with Differently Shaped Transverse Ribs. Journal of Applied Mathematics. https://doi.org/10.1155/2011/323485

Manning, F. S., \& Thompson, R. E. (1995). Oilfield Processing Volume Two: Crude Oil. USA: Tulsa: PennWell Publishing Company.

Oon, C. S., Togun, H., Abdulrazzaq, T., Kazi, S. N., Badarudin, A., Kadhum, A. A. H., \& Sadeghinezhad, 
E. (2014). A Review of Studies on Forced, Natural and Mixed Heat Transfer to Fluid and Nanofluid Flow in an Annular Passage. Renewable and Sustainable Energy Reviews, 39(November 2014), 835856. https://doi.org/10.1016/j.rser.2014.07.008

Ramires, M. L. V., \& Nieto de Castro, C. A. (1994). Standard Reference Data for the Thermal Conductivity of Water. American Institute of Physics and American Chemical Society, 1, 1377-1381.

Sharma, K. V., Sarma, P. K., Azmi, W. H., Mamat, R., \& Kadirgama, K. (2012). Correlations to Predict friction and Forced Convection Heat Transfer Coefficients of Water Based Nanofluids for Turbulent Flow in a Tube. International Journal of Microscale and Nanoscale Thermal and Fluid Transport Phenomena, 3(4), 1-25.

Sinnott, R. K. (2005). Coulson and Richardson's Chemical Engineering Series: Chemical Engineering Design, Vol. 6, Fourth Edition. England: Elsevier.

Skočilasová, B., Skočilas, J., \& Soukup, J. (2018). Forced Convection and Heat Transfer Around a Bounded Cylinder. MATEC Web of Conferences, 157, 1-8. https://doi.org/10.1051/matecconf/201815702045 